\title{
Vulnerabilidade e as violências mais comuns enfrentadas pelas mulheres brasileiras
}

\author{
Vulnerability and the most common violence faced by brazilian women \\ Vulnerabilidad y violencia más común que enfrentan las mujeres brasileñas
}

Nayandra da Silva Tinoco ${ }^{1 *}$, Adriene Roberta Costa dos Santos ${ }^{1}$, Salinny da Silva Ferreira Fialho Raquel De Souza Redman ${ }^{1}$, Alaine Naielly da Silva Lima ${ }^{1}$, Janeide de Souza dos Santos ${ }^{1}$, Suellen Karine da Silva Rocha ${ }^{1}$, Cheila Aparecida Almenares Costa ${ }^{1}$, Dablina Jasmine Farias Colares Serrão ${ }^{1}$, Silvana Nunes Figueiredo'.

\section{RESUMO}

Objetivo: Identificar quais são as vulnerabilidades das mulheres brasileiras e sua relação com os tipos mais comuns de violência. Métodos: Trata-se de um estudo descritivo exploratório onde optou-se por métodos de Revisão Integrativa de Literatura (RIL). A busca por publicações cientificas foi realizada de abril de 2019 a outubro de 2020, utilizando-se bibliotecas virtuais: Biblioteca Virtual em Saúde (BVS), LILACS e Scientific Electronic Library Online (SCIELO). Resultados: A maior parte dos artigos utilizados é de 2018, a faixa etária manteve-se diversificada e a maioria das mulheres eram pretas ou pardas, casadas e com baixo nível de escolaridade, os tipos de violência mais comuns foram a violência psicológica seguida da física, o principal agressor costuma ser o parceiro íntimo e o local de ocorrência da violência costuma ser a residência da vítima. Considerações finais: Portanto, é observado que quando as mulheres são pretas ou pardas e com baixo nível escolar as chances de serem vítimas aumenta, o que mostra a necessidade de se conhecer o perfil da mulher que sofre violência.

Palavras-chave: Saúde da mulher, Violência contra a mulher, Violência de gênero, Direitos da mulher.

\begin{abstract}
Objective: To identify the vulnerabilities of brazilian women and their relationship with the most common types of violence. Methods: This is an exploratory descriptive study in which the Integrative Literature Review (RIL) methods were chosen. The search for scientific publications was carried out from April 2019 to October 2020 , using virtual libraries: Virtual Health Library (VHL), LILACS and Scientific Electronic Library Online (SCIELO). Results: Most of the articles used are from 2018, the age group remained diverse and most women were black or brown, married and had a low level of education, the most common types of violence were psychological followed by physical, the main aggressor is usually the intimate partner and the place where the violence occurs is usually the victim's home. Final considerations: Therefore, it is observed that when women are black or brown and have a low educational level, the chances of being victims increase, which shows the need to know the profile of women who suffer violence.
\end{abstract}

Key words: Women's health, Violence against women, Gender violence, Women's rights.

\section{RESUMEN}

Objetivo: Identificar las vulnerabilidades de las mujeres brasileñas y su relación con los tipos de violencia más comunes. Métodos: Se trata de un estudio descriptivo exploratorio en el que se eligieron los métodos de Revisión Integrativa de Literatura (RIL). La búsqueda de publicaciones científicas se realizó desde abril de 2019 hasta octubre de 2020, utilizando bibliotecas virtuales: Biblioteca Virtual en Salud (BVS), LILACS y Biblioteca Electrónica Científica en Línea (SCIELO). Resultados: La mayoría de los artículos utilizados son de 2018, el grupo de edad se mantuvo diverso y la mayoría de las mujeres eran negras o morenas, casadas y con bajo nivel educativo, los tipos de violencia más comunes fueron la violencia psicológica seguida de la violencia física, el agresor principal suele ser la pareja íntima y el lugar donde se produce la violencia suele ser el domicilio de la víctima. Consideraciones finales: Por tanto, se observa que cuando las mujeres son negras o morenas y tienen un nivel educativo bajo, aumentan las posibilidades de ser víctimas, lo que demuestra la necesidad de conocer el perfil de las mujeres que sufren violencia.

Palabras clave: Salud de la mujer, Violencia contra la mujer, Violencia de género, Derechos de la mujer.

${ }^{1}$ Centro Universitário de Manaus (CEUNI), Manaus - AM. *E-mail: tinoconayandra@gmail.com

SUBMETIDO EM: 11/2020

PUBLICADO EM: 3/2021 


\section{INTRODUÇÃO}

A violência contra a mulher é um grande problema de saúde pública. É reconhecida como uma quebra dos direitos humanos, atingindo não somente o direito à vida, mas também a saúde física e mental, pautadas na questão de gênero, podendo ocorrer tanto em ambientes públicos como privados (ARBOIT J, et al., 2017).

Segundo Acosta DF (2017) informa que é um problema fundamentado nas relações de poder, entre homens e mulheres, e nas desigualdades entre os mesmos que foram construídos ao longo da história, onde a violência se instalou sob o poder machista, deixando a mulher a mercê de vários tipos de violência na atualidade. As formas de violência contra a mulher podem ser físicas, sexuais, psicológicas, patrimoniais e morais (FERREIRA PC, et al., 2020). Há uma estimativa de que aproximadamente $35 \%$ das mulheres sofrem violência física ou sexual em todo o mundo, sendo que na maior parte das vezes o agressor é o próprio parceiro (LIMA LAA, et al., 2016).

Hoepers e Tomanik dizem que a violência é algo tão antigo quanto à história da humanidade e pode ser expressa nos mais variados contextos sociais. Podemos ver um claro exemplo de violência contra a mulher na passagem bíblica de $2^{\circ}$ Samuel capítulo 13 dos versículos 12 a 14, onde é contada a história de Tamar que é drasticamente violentada por seu meio irmão Amnon. Nesta passagem é possível ler Tamar expressando de maneira verbal a sua oposição a aproximação do irmão, indagando- o sobre como ela viveria naquele tempo depois de ter passado por tamanha vergonha, porém mesmo assim seu irmão Amnon não a deixa ir, pelo contrário ele usa de força física para conter Tamar e a violenta-lá (GUIMARAES RCS, et al., 2018).

Apesar desta ser uma história antiga Pietersen e Fourie dizem que ela continua a ser a história de muitas outras mulheres que não têm a sua voz ouvida, como aconteceu com Tamar que apesar de implorar para que seu meio irmão não a desonrasse ele ainda assim recusa-se a ouvir o seu pedido e a estupra, depois ainda a humilha pedindo para que ela saia de sua casa o mais rápido possível (VAN DER WALT C, 2012).

Este texto é um claro indicativo das relações de poder que ocorrem entre homens e mulheres desde a antiguidade Pinafi T (2007), diz que na Grécia antiga as mulheres além de não possuírem nenhum poder jurídico, também não tinha acesso a uma educação e não podiam sair de suas casas desacompanhadas como era permitido aos homens, da mesma maneira acontecia em Roma, onde as mulheres eram vistas junto com as crianças e os escravos, como pessoas de menor valor para a sociedade, cujo qual a única função era ter filhos. Enquanto os homens podiam estudar política, artes e letras, as mulheres ficavam em casa apenas cuidando do lar e de suas crianças (MAFIOLETTI TM, et al., 2018).

É com o advento da revolução francesa no século 17 que Saes LAM e Morin TM (2017) dizem que as mulheres passaram a se destacar como participantes ativas das grandes mobilizações populares, além disso, elas também começam a se inserir na política interna da França o que de acordo com Pinafi T (2007), acontece porque essas mulheres acreditavam que as ideias de igualdade, fraternidade e liberdade deveriam também ser estendidas a elas (ROSA DOA, et al., 2018; MAFIOLETTI TM, et al., 2018).

Em 1946 a Organização das Nações Unidas (ONU) cria a comissão de status da mulher (CSW) onde afirmava-se que homens e mulheres deveriam ter direitos iguais e que a liberdade deveria ser aplicada igualmente a ambos os gêneros (MAFIOLETTI TM, et al., 2018).

Um marco importante na luta das mulheres contra as desigualdades de gênero acontece no dia 8 de março de 1957 na cidade de Nova York - Estados Unidos da América, onde um grupo de operárias de uma fábrica têxtil inicia uma greve em busca de melhorias nas condições de trabalho, uma carga horária reduzida e salários iguais aos dos homens, essas mulheres então acabam sendo vítimas de um incêndio dentro da fábrica onde 130 tecelãs morrem carbonizadas e é em homenagem a esse grupo que durante uma conferência na Dinamarca é criado no dia 8 de março de 1910 o Dia internacional da mulher, que é comemorado até os dias atuais (LIRA KFS, 2019).

A partir desse marco histórico as lutas das mulheres contra as desigualdades impostas a elas passam a se fortalecer mais ainda e mais políticas públicas começam a ser criadas, inclusive no Brasil. É então que em 1984, o Ministério da Saúde cria o Programa de Assistência Integral à Saúde da Mulher (PAISM), cujos 
princípios são a descentralização, hierarquização e regionalização dos serviços de saúde voltados a mulher, este programa deveria englobar todas as necessidades da mulher brasileira, como por exemplo, prestar assistência ao pré-natal, parto, puerpério, planejamento familiar, ISTs e tratamento para os tipos de cânceres que mais acometem as mulheres (BRASIL, 2004).

Em 1985, considerado o ponto alto da declarada pela ONU a década das mulheres, por ser a década em que as primeiras conquistas e políticas públicas implementadas para o enfretamento da violência contra as mulheres são conhecidas, que também ocorre a inauguração da primeira delegacia de defesa da mulher no Brasil e a criação do Conselho Nacional dos Direitos da Mulher (BRASIL, 2011).

Em 1995 o Brasil inicia sua participação na Convenção de Belém do Pará que tinha como objetivo a prevenção, punição e erradicação da violência contra a mulher entre os países da América. A primeira edição da Norma técnica para prevenção e tratamento dos agravos resultantes da violência sexual sofrida por mulheres e adolescentes foi publicada pelo ministério da saúde em 1999, nela continha algumas recomendações sobre o atendimento, o apoio psicossocial e os protocolos profiláticos para este tipo de situação. Houve ainda mais duas edições em 2005 e 2012 (MAFIOLETTI TM, et al., 2018; PINAFI T, 2007).

A partir de 2003 com a criação da Secretaria Nacional de Políticas para as mulheres as políticas de enfrentamento a violência contra a mulher passam a ter uma gestão mais elaborada com a inserção de diretrizes, normas, ações e estratégias para o monitoramento deste tipo de violência, ocorre também um incentivo a projetos que visam à prevenção da violência contra a mulher e a legislação começa a passar por um aperfeiçoamento. Um decreto de número 9.417 do dia 20 de junho de 2018, transfere a Secretaria Nacional de Políticas para Mulheres para a estrutura organizacional do Ministério dos Direitos Humanos (BRASIL, 2011; BRASIL, 2020).

Em 7 de agosto de 2006 é promulgada a lei de número 11.340, conhecida como Lei Maria da Penha que declara em seu artigo $1^{\circ}$ que:

"Esta Lei cria mecanismos para coibir e prevenir a violência doméstica e familiar contra a mulher, nos termos do $\S 8^{\circ}$ do art. 226 da Constituição Federal, da Convenção sobre a Eliminação de Todas as Formas de Violência contra a Mulher, da Convenção Interamericana para Prevenir, Punir e Erradicar a Violência contra a Mulher e de outros tratados internacionais ratificados pela República Federativa do Brasil; dispõe sobre a criação dos Juizados de Violência Doméstica e Familiar contra a Mulher; e estabelece medidas de assistência e proteção às mulheres em situação de violência doméstica e familiar" (BRASIL, 2006).

A partir de então é possível notar um aumento no interesse de se ter dados que possam ajudar na criação de políticas públicas para o enfretamento da violência contra as mulheres. Em 2018 o Sistema de Informação de Agravos e Notificação (SINAN) registrou no Brasil 350.354 atendimentos relacionados a violência doméstica, sexual e/ou outras violências, sendo que em 252.668 das vezes as vítimas eram mulheres e em 62.802 dos casos o tipo de violência foi considerada psicomoral (BRASIL, 2011; SILVA MPS, et al., 2017).

Para se combater de maneira efetiva a violência contra a mulher é necessário que os setores de saúde, segurança pública, justiça, educação e assistência social, consigam juntos propor ações que irão ajudar na desconstrução das desigualdades de gênero, combater as discriminações e promover o empoderamento da mulher, além de garantir um atendimento qualificado e humanizado as mulheres em situações de vulnerabilidade. Portanto, o enfretamento a violência contra a mulher está diretamente ligado a prevenção, a assistência e a garantia de direitos das mulheres (BRASIL, 2011).

Diante do exposto, essa pesquisa tem o objetivo de descrever sobre a vulnerabilidade e as violências mais comuns enfrentada pela mulher brasileira.

\section{MÉTODOS}

Trata-se de um estudo descritivo exploratório onde optou-se por métodos de Revisão Integrativa de Literatura (RIL) com finalidade de investigar a respeito vulnerabilidade e as violência mais comuns enfrentadas 
pela mulher brasileira possibilitando identificar quais são as vulnerabilidades da mulher brasileira e sua relação com os tipos mais comuns de violência.

A busca por publicações cientifica foi realizada de abril de 2019 a outubro de 2020, utilizando-se bibliotecas virtuais: Biblioteca Virtual em Saúde (BVS), LILACS e Scientific Eletronic Library Online (SCIELO), mediante seguintes descritores: "saúde da mulher", "violência contra a mulher", "violência de gênero" e "direitos da mulher". No que tange aos critérios de elegibilidade: artigos publicados nos últimos 5 anos (2015-2020), português e inglês, completos e disponíveis gratuitamente. Critérios de inelegibilidade: artigos em forma de resumo, monografias, dissertação de mestrado.

Para atingir o objetivo, foi definida a seguinte pergunta norteadora do estudo: Quais são as vulnerabilidades da mulher brasileira e sua relação com os tipos de violência sofrido pelas mesmas?

\section{RESULTADOS E DISCUSSÃO}

Após a busca dos artigos através das bases de dados científicas utilizando os seguintes descritores: saúde da mulher, violência contra a mulher, apresentamos os seguintes resultados em cada base de dados, no SCIELO, foi encontrado 716 dos quais 625 estavam disponíveis em português, 64 em espanhol e 335 em inglês. Na plataforma LILACS foram encontrados 1376 artigos dos quais 910 estavam disponíveis em português, 721 em espanhol e 570 em inglês, utilizando os critérios de elegibilidade como: artigos publicados nos últimos cinco anos, sendo apenas em inglês ou português, estando disponíveis de maneira completa e gratuita, chegou-se ao resultado de 8 artigos na base de dados SCIELO e 6 artigos na base de dados LILAS (Figura 1).

Figura 1 - Fluxograma dos artigos encontrados nas bases de dados científicas.

\begin{tabular}{|c|c|}
\hline SCIELO - 716 artigos & LILACS - 1376 artigos \\
\hline Português -625 artigos & Português -910 artigos \\
\hline Espanhol -64 artigos & Espanhol -721 artigos \\
\hline Inglês -335 artigos & Inglês -570 artigos \\
\hline
\end{tabular}

Após critérios de Elegibilidade e Exclusão

Os seguintes artigos foram selecionados para serem inclusos na discussão

SCIELO - 8 artigos

LILACS -6 artigos

Fonte: Tinoco NS, et al., 2020. 
Quadro 1 - Apresentação da síntese de artigos quanto aos autores, título, idioma, plataforma e resultados.

\begin{tabular}{|c|c|c|c|c|c|}
\hline Número & Autor(es) & Título & Idioma & Plataforma & Resultados \\
\hline 1 & Lira KFS (2019) & $\begin{array}{l}\text { Relações de gênero, poder e } \\
\text { violência contra as mulheres: Um } \\
\text { estudo sobre o Sertão brasileiro. }\end{array}$ & Português & Scielo & $\begin{array}{l}\text { Faixa etária diversificada, tipo mais comum de violência foi a física } \\
\text { seguida da psicológica, citaram o medo de se separar do autor das } \\
\text { agressões para não destruir sua família, na maioria das vezes o } \\
\text { agressor foi o marido e o local de ocorrência foi a residência da vítima. }\end{array}$ \\
\hline 2 & $\begin{array}{l}\text { Oliveira CAB, et } \\
\text { al. (2019) }\end{array}$ & $\begin{array}{l}\text { Perfil da vítima e características } \\
\text { da violência contra a mulher no } \\
\text { estado de Rondônia - Brasil }\end{array}$ & Português & Scielo & $\begin{array}{l}\text { A faixa etária mais afetada estava entre } 19 \text { a } 39 \text { anos, solteiras, negras } \\
\text { e/ou pardas e que possuíam baixo nível escolar. A violência mais comum } \\
\text { foi a física seguida da sexual. O autor costuma ser o parceiro e as } \\
\text { agressões ocorrem na maioria das vezes em casa. }\end{array}$ \\
\hline 3 & $\begin{array}{l}\text { Rosa DOA, et } \\
\text { al. (2018) }\end{array}$ & $\begin{array}{l}\text { Violência provocada pelo parceiro } \\
\text { íntimo entre usuárias da Atenção } \\
\text { Primária à Saúde: prevalência e } \\
\text { fatores associados }\end{array}$ & Português & Scielo & $\begin{array}{l}\text { A maior parte das mulheres eram casadas e com baixo nível escolar. O } \\
\text { tipo de violência mais frequente foi a psicológica seguida da física, a } \\
\text { maior parte das agressões eram realizadas pelo parceiro íntimo. Ficou } \\
\text { perceptível a dificuldade das mulheres de buscarem ajuda ou por medo, } \\
\text { vergonha, ou dificuldade de se expor, fazendo com que elas acabem } \\
\text { desenvolvendo sintomas físicos e psicológicos. }\end{array}$ \\
\hline 4 & $\begin{array}{l}\text { Guimaraes } \\
\text { RCS, et al. } \\
\quad(2018)\end{array}$ & $\begin{array}{l}\text { Impacto na autoestima de } \\
\text { mulheres em situação de } \\
\text { violência doméstica atendidas em } \\
\text { Campina Grande, Brasil }\end{array}$ & Português & Scielo & $\begin{array}{l}\text { A faixa etária predominante foi de } 20 \text { a } 68 \text { anos, casadas. A percepção } \\
\text { que elas possuíam de si próprias depois de terem sofrido algum tipo de } \\
\text { violência eram sentimentos de inferioridade, insatisfação consigo mesma } \\
\text { e até uma revolta contra si própria. }\end{array}$ \\
\hline 5 & $\begin{array}{l}\text { Leite FMC, et al. } \\
\qquad(2017)\end{array}$ & $\begin{array}{l}\text { Violência contra a mulher em } \\
\text { Vitória, Espírito Santo, Brasil }\end{array}$ & Inglês & Scielo & $\begin{array}{l}\text { As mulheres em sua maioria tinham menos de } 40 \text { anos, pardas, } \\
\text { divorciadas, a violência psicológica foi a mais frequente seguida da física } \\
\text { e o agressor costuma ser o parceiro íntimo. }\end{array}$ \\
\hline 6 & $\begin{array}{l}\text { Smaniotto GRG, } \\
\text { et al. (2018) }\end{array}$ & $\begin{array}{l}\text { Situações de vulnerabilidade a } \\
\text { violência vivenciadas por } \\
\text { mulheres profissionais do sexo: } \\
\text { Um estudo de caso }\end{array}$ & Português & Scielo & $\begin{array}{l}\text { As entrevistadas tinham em média } 25 \text { anos, com baixo nível escolar, } \\
\text { eram profissionais do sexo, o agressor costuma ser o cliente e o local de } \\
\text { ocorrência é a casa de programa. Foi observado que o trabalho das } \\
\text { mesmas é cheio de situações que as colocam vulneráveis a possíveis } \\
\text { agressões de todos os tipos. O maior medo delas é de serem estupradas. }\end{array}$ \\
\hline 7 & $\begin{array}{l}\text { Leite FMC, et al. } \\
\qquad(2015)\end{array}$ & $\begin{array}{l}\text { Violência contra a mulher: } \\
\text { caracterizando a vítima, a } \\
\quad \text { agressão e o autor }\end{array}$ & Português & LILACS & $\begin{array}{l}\text { As mulheres entrevistadas estavam na faixa dos } 30 \text { a } 39 \text { anos, ensino } \\
\text { médio completo, brancas e divorciadas. Ocorreu predominantemente } \\
\text { violência física, psicológica e moral. O agressor costumava ser o } \\
\text { companheiro e o local da ocorrência era a residência da vítima. As } \\
\text { mulheres desenvolvem insegurança e é extremamente difícil para elas } \\
\text { quebrarem o ciclo da violência em que estão inseridas. }\end{array}$ \\
\hline
\end{tabular}




\begin{tabular}{|c|c|c|c|c|c|}
\hline Número & Autor(es) & Título & Idioma & Plataforma & Resultados \\
\hline 8 & $\begin{array}{l}\text { Santos DF, et } \\
\text { al. (2017) }\end{array}$ & $\begin{array}{l}\text { Percepção de mulheres acerca } \\
\text { da violência vivenciada }\end{array}$ & Português & LILACS & $\begin{array}{l}\text { As mulheres tinham uma média de idade de } 34 \text { anos, ensino médio } \\
\text { completo e pretas ou pardas. A maioria alega ter sofrido violência } \\
\text { psicológica associada a física por parte do companheiro da época e } \\
\text { dentro de sua residência. Eram feitas ameaças, humilhações que faziam } \\
\text { com que essas mulheres tivessem medo do agressor, se isolassem } \\
\text { dentro de si mesmas fazendo que ficassem mais suscetíveis a quadros } \\
\text { depressivos, demonstravam decepção com o parceiro. }\end{array}$ \\
\hline 9 & $\begin{array}{l}\text { Siqueira VB, et } \\
\text { al. (2018) }\end{array}$ & $\begin{array}{l}\text { Violência psicológica contra } \\
\text { mulheres usuárias da atenção } \\
\text { primária à saúde }\end{array}$ & Português & LILACS & $\begin{array}{l}\text { Mulheres na média dos } 36 \text { anos, casadas, pretas ou pardas, com ensino } \\
\text { superior, o tipo de violência predominante foi a violência psicológica pelo } \\
\text { companheiro }\end{array}$ \\
\hline 10 & $\begin{array}{l}\text { Fanger VC, et } \\
\text { al. (2019) }\end{array}$ & $\begin{array}{l}\text { Fatores associados à violência } \\
\text { contra mulher na vida pregressa } \\
\text { de mulheres encarceradas }\end{array}$ & Português & LILACS & $\begin{array}{l}\text { A média de idade foi de } 39 \text { anos, pretas ou pardas, solteiras ou } \\
\text { divorciadas. O tipo mais comum de violência foi a psicológica seguida } \\
\text { física e sexual. }\end{array}$ \\
\hline 11 & $\begin{array}{l}\text { Mascarenhas } \\
\text { MDM, et al. } \\
(2020)\end{array}$ & $\begin{array}{l}\text { Análise das notificações de } \\
\text { violência por parceiro íntimo } \\
\text { contra mulheres, Brasil, 2011- } \\
2017\end{array}$ & Português & SCIELO & $\begin{array}{l}\text { Os tipos de violência mais relatados foram física }(86,6 \%) \text { e psicológica } \\
(53,1 \%) \text {. A faixa etária predominante foi de } 20 \text { a } 39 \text { anos, com baixo nível } \\
\text { de escolaridade, pretas ou pardas. Das } 10 \text { notificações feitas em } 6 \text { dos } \\
\text { casos o agressor costumava ser o parceiro íntimo e as ocorrências } \\
\text { geralmente aconteciam em casa, mais de uma vez. }\end{array}$ \\
\hline 12 & $\begin{array}{l}\text { Bernardino IM, } \\
\text { et al. (2016) }\end{array}$ & $\begin{array}{l}\text { Violência contra mulheres em } \\
\text { diferentes estágios do ciclo de } \\
\text { vida no Brasil: um estudo } \\
\text { exploratório }\end{array}$ & Português & SCIELO & $\begin{array}{l}\text { O tipo mais comum de violência foi a física seguida da verbal e } \\
\text { psicológica, a média de idade das mulheres foi de } 35 \text { anos, com baixo } \\
\text { nível de escolaridade. Em } 93 \% \text { das vezes os agressores eram homens } \\
\text { o local de ocorrência era na residência da vítima. }\end{array}$ \\
\hline 13 & $\begin{array}{l}\text { Silva MPS, et al. } \\
\text { (2017) }\end{array}$ & $\begin{array}{l}\text { A violência e suas repercussões } \\
\text { na vida da mulher contemporânea }\end{array}$ & Português & LILACS & $\begin{array}{l}\text { O presente estudo demonstrou que as mulheres mais atingidas pela } \\
\text { violência estão na faixa dos } 30-49 \text { anos seguido da dos de } 20-29 \text { anos, } \\
\text { em sua maioria pardas, com baixo nível de escolaridade, solteiras em sua } \\
\text { maioria e os tipos mais comuns de violência sofrido foram psicológica, } \\
\text { física e sexual nesta ordem. }\end{array}$ \\
\hline 14 & $\begin{array}{l}\text { Viana AL, et al. } \\
\qquad(2018)\end{array}$ & Violência contra a mulher & Português & LILACS & $\begin{array}{l}\text { De todas as notificações de violência contra a mulher presentes neste } \\
\text { estudo, } 61 \% \text { foram contra mulheres entre } 25 \text { e } 59 \text { anos, pardas ou pretas, } \\
\text { solteiras, com baixo nível de escolaridade, as agressões em sua maioria } \\
\text { ocorriam na residência da vítima, sendo a física a mais comum e os } \\
\text { agressores costumavam ser o companheiro. }\end{array}$ \\
\hline
\end{tabular}


A maior parte das publicações utilizadas é do ano de 2018 com 5 artigos $(35,72 \%)$ seguido por 2019 e 2017 com 3 artigos cada (21,43\%), 2015, 2016 e $2020 \mathrm{com} 1$ artigo cada (7,14\%) todos os estudos foram realizados no Brasil, predominou-se artigos publicado em português (13-92,86\%) e apenas um em inglês (7,14\%). Em sua maioria o método de estudo utilizado foi de caráter quantitativo e análise descritiva.

Dentre os artigos citados a faixa etária foi bastante diversificada indo desde 19 até os 68 anos, similar ao estudo realizado por Batista onde a faixa etária foi de 21 a 58 anos. Dos 14 artigos em 8 as mulheres se autodeclaravam pretas ou pardas, em 4 não foi citado nenhum tipo de raça, em 1 artigo a maioria das vítimas eram mulheres brancas e 1 artigo relata que houve uma grande diversificação de raças entre as mulheres participantes, o que segundo Lira demonstra que a violência contra a mulher não está restringida a um grupo especifico de mulheres, mas está amplamente difundido na sociedade podendo atingir mulheres de qualquer faixa etária, raça ou grau de escolaridade (LEITE FMC, et al., 2017; BATISTA VC, et al., 2020).

Quanto ao estado civil as mulheres eram em sua maioria casadas (4) seguido por solteiras (3), divorciadas (3), não informaram (3) e solteiras ou divorciadas (1). Quanto a escolaridade a maioria possuía um baixo nível escolar (9), seguido por ensino médio completo (2), ensino superior completo (1), não informado (2) corroborando com o estudo feito por Costa MS, et al. (2015) em que as principais vítimas também possuíam baixo nível escolar, eram casadas e do lar o que para Ferreira PC, et al. (2020) ocorre devido ao fato de pessoas com baixo nível de escolaridade terem medo de fazer a denúncia, enquanto que mulheres com maior grau de instrução acabam sendo menos toleráveis a relacionamentos violentos (FIOROTTI K, et al., 2018).

Em relação a percepção das mulheres acerca da violência vivenciada é citado o medo de se separar do agressor quando ele é o seu parceiro íntimo não querendo ser colocada como a culpada de ter destruído sua família. Além da insegurança da vítima em relação aos sentimentos demonstrados que variam desde o domínio do homem e a submissão da mulher a grande decepção com o parceiro diante do relacionamento violento em que está inserida, as mulheres passam então a criar um olhar negativo acerca do seu relacionamento definindo como algo ruim e conflituoso (LIRA KFS, 2019; SANTOS DF, et al., 2017).

Santos DF, et al. (2017) diz que um relacionamento onde a violência está presente acaba sendo instável e a mulher é apenas vista como um objeto por parte do seu companheiro. Além disso o medo passa a ser algo constante na vida dessas mulheres as paralisando das suas ações cotidianas e as isolando de todos, fazendo a sentirem privadas o que aumenta a possibilidade de se desenvolver algum tipo de doença tanto de ordem mental como física. Portanto se faz necessário que a mulher reconheça a gravidade da situação em que está inserida para que desta maneira possa buscar ajuda e apoio de profissionais especializados.

A dificuldade das vítimas em buscar ajuda ou realizar a denúncia ocorre por medo, vergonha, constrangimento frente a exposição que vão enfrentar, ou por serem dependentes financeiramente ou emocionalmente do seu agressor, o que faz com que em muitos dos casos elas acabem desenvolvendo sintomas físicos e psicológicos (ROSA DOA, et al., 2018).

Sobre mulheres vítimas de violência em situação rural em que as participantes citam a dependência financeira como um dos motivos para não denunciarem, além disso elas também citam o fato de não se sentirem preparadas para viverem sem o apoio financeiro do seu companheiro, o que piora quando essas mulheres possuem filhos, devido ao fato delas acreditarem que uma separação traria sofrimento aos mesmos. A situação em que essas mulheres estão inseridas traz consigo uma visão de que as mesmas devem se conformar com as circunstâncias em que vivem, pois a violência está presente na vida delas por toda a vida, onde muitas vezes as suas próprias mães passam para elas que tais situações são normais, devido ao forte cenário machista em que estão inseridas, onde é comum que o homem exerça um poder autoritário sobre a mulher, as convencendo de que elas não tem valor nenhum e que não conseguiriam viver sem eles, dificultando a busca por ajuda dessas mulheres (BERVIAN G, et al., 2019).

A percepção que elas acabam criando de si mesmas após terem sofrido algum tipo de violência vão desde sentimentos de inferioridade, insatisfação consigo mesma, até uma revolta contra si, o que em alguns casos pode levar ao desenvolvimento de problemas como: ansiedade, depressão, ideias paranoides e acúmulo de problemas no seu cotidiano (GUIMARAES RCS, et al., 2018). Algumas mulheres relatam o fato de se sentirem a pior pessoa do mundo, em suas próprias palavras, além de vivenciarem o sentimento de humilhação pelo 
parceiro. As indagações que as mulheres relatam após a violência realizada pelo parceiro é principalmente devido ao fato de elas não terem feito nada de errado aos seus olhos e serem punidas indevidamente (ZANCAN N, et al., 2013).

Tais resultados vão de encontro ao estudo realizado por Batista VC, et al., (2020) que cita o medo das agressões como sendo um constante companheiro dessas mulheres o que fazia com que elas estivessem constantemente apreensivas quanto ao momento em que poderia acontecer a próxima agressão. Além disso, as relações de poder onde o homem era visto como dominante e a mulher como submissa estavam presentes em situações onde ele determinava como elas deveriam se comportar, se vestir, quando poderiam sair de casa ou em situações em que elas eram obrigadas a usar substâncias ilícitas. Os sentimentos de infelicidade, desconfiança e descrédito no amor se tornam cada vez mais presentes, além do desenvolvimento de depressão entre outras enfermidades.

Em um dos artigos citados sobre vulnerabilidade da violência a mulheres profissionais do sexo foi visto que o trabalho exercido por elas traz consigo muitas situações que a deixam vulneráveis a sofrerem algum tipo de violência indo desde humilhações verbais, psicológicas e até agressões físicas (SMANIOTTO GRG, et al., 2018).

Quanto aos tipos mais comuns de violência esteve presente a violência psicológica seguida da física em 5 artigos, violência física seguida da psicológica em 4 artigos, 2 artigos não informam o tipo mais prevalente de violência, violência física seguido da sexual esteve presente em 1 artigo, em 1 artigo a violência mais prevalente foi a psicológica, e em outro apenas a violência física.

Os resultados acima citados vão de encontro ao estudo realizado por Silva LEL e Oliveira MLC (2016), sobre as características epidemiológicas da violência contra a mulher no Distrito Federal entre 2009 e 2012 em que mais de um tipo de violência esteve presente simultaneamente.

Leite FMC, et al. (2017) observa que a violência psicológica está geralmente associada a violência física demonstrando que nem sempre as agressões irão iniciar já de maneira física, mas começam pela privação de liberdade e vão avançando até causarem constrangimentos, humilhações e demonstrações físicas de agressão corroborando com o estudo de Costa em que a violência psicológica foi caracterizada como a primeira acontecer sendo menos percebida pela sociedade, pois são as violências físicas e sexuais que estão mais em destaque (COSTA MS, et al., 2015).

O que também está em concordância com o que Mascarenhas MDM, et al. (2020), relata em seu artigo sobre a dificuldade da mulher em entender que está sim sendo vítima de um tipo de violência quando esta é apenas a psicológica. Em muitos casos essas mulheres só irão procurar os serviços de saúde quando começam a apresentar problemas crônicos, tais como, síndrome do pânico, ou seja, um profundo medo de sair de casa, depressão, dores crônicas e até mesmo podendo chegar a tentativas de suicídio.

Silva MPF, et al. (2017), relata que quando ocorre apenas a violência psicológica as mulheres tendem a relevar com mais frequência dando a entender de que aqueles atos por elas sofridos não são tão graves assim a ponto de serem denunciados às autoridades e o agressor punido.

Em relação ao vínculo da vítima com o agressor em 11 artigos o parceiro íntimo apareceu como sendo na maioria das vezes o autor da violência, em 2 artigos não foi informado quem foi o principal autor das agressões e em um artigo o autor era o cliente das profissionais do sexo. Quanto ao local da ocorrência da agressão a maioria ocorreu na residência da vítima (7), seguido por local não informado no artigo (6) e um artigo cita como local da ocorrência uma casa de programa.

Resultados estão em concordância com Silva LEL e Oliveira MLC (2016) onde se vê uma elevada incidência de agressões cometidas dentro da residência da vítima e Borburema TLR, et al., (2017) onde os achados identificaram como o principal agressor das mulheres o seu cônjuge, o que demonstra um tipo de violência baseada no gênero juntamente com uma desigualdade de privilégios, direitos e deveres.

Mesmo o cônjuge da vítima sendo relatado como o principal acusado das agressões ainda assim a maioria das mulheres do estudo encontrava-se em união estável e duradoura o que demonstra a dificuldade que a mulher possui de romper com o ciclo da violência em que está inserida, entre os motivos citados para 
permanência no relacionamento estava a dependência financeira. Além disso, é visto que a maioria das mulheres foram vítimas de violência dentro de suas próprias casas, local onde elas deveriam se sentir seguras e amadas, entretanto tornou-se um ambiente de humilhações, agressões e constantes ameaças vindas do seu companheiro (COSTA MS, et al., 2015).

Quando a mulher sofre algum tipo de violência e de alguma maneira internaliza o medo que sente ela acaba se tornando prisioneira da situação em que está posta, o que faz com ela leve um tempo para entender que é necessário haver um rompimento desta relação e um resgate dos seus próprios valores, pois a violência se inicia de uma forma lenta e silenciosa, gerando consequências (CARNEVALLE CV, et al., 2019).

\section{CONSIDERAÇÕES FINAIS}

Durante toda a sua vida as mulheres estão vulneráveis a sofrerem qualquer tipo de violência vindo de qualquer parte, tanto de seus companheiros íntimos como de desconhecidos, quando estas são pretas ou pardas e com baixo nível escolar as chances de serem vítimas aumentam mais ainda, o que demonstra a necessidade de se conhecer o perfil da mulher vítima de violência, mostrando assim as suas vulnerabilidades e usando estes conhecimentos para produzir ferramentas que vão ajudar no combate contra este tipo de agressão.

\section{REFERÊNCIAS}

1. ACOSTA DF. Aspectos éticos e legais no cuidado de enfermagem ás vítimas de violência doméstica. Texto contexto - enferm. 2017.26(3): e6770015

2. ARBOIT J, et al. Atenção à saúde de mulheres em situação de violência: desarticulação dos profissionais em rede. Rev. esc. enferm. USP. 2017. 51: e03207

3. BATISTA VC, et al. Prisioneiras do sofrimento: percepção de mulheres sobre a violência praticada por parceiros íntimos. Rev. Bras. Enferm. 2020. 73(1): e20190219

4. BERNARDINO IM, et al. Violência contra mulheres em diferentes estágios do ciclo de vida no Brasil: um estudo exploratório. Rev. bras. Epidemiol. 2016. 19(4):740-52

5. BERVIAN G, et al. Violência contra mulheres rurais: concepções de profissionais da rede intersetorial de atendimento. Revista Enferm. Global. 2019. 18(54):144-179.

6. BÍBLIA SAGRADA: Nova Versão Transformadora. Tradução TyndaleHouse Foundation. São Paulo. Mundo Cristão, 2016. 2 Samuel, Capítulo 13, versículo 12-14.

7. BORBUREMA TLR, et al. Violência contra mulher em contexto de vulnerabilidade social na Atenção Primária: registro de violência em prontuários. Rev. bras. med. fam. Comunidade. 2017. 12(39):1-13

8. BRASIL. Política Nacional de Atenção Integral á Saúde da mulher: Principios e Diretrizes. Ministério da saúde. Brasília - DF; 2004. $1^{\circ}$ ed.

9. BRASIL. Política Nacional de Enfrentamento a Violência Contra as Mulheres. Secretaria Nacional de Enfrentamento à Violência contra Mulheres. Brasília - DF; 2011.

10. BRASIL. Secretaria Nacional de Políticas para as Mulheres (SNPM). 2020.

11. BRASIL. Lei n.11.340 de 07 de agosto de 2006. Dispõe sobre a criação dos Juizados de Violência Doméstica e Familiar contra a Mulher; altera o Código de Processo Penal, o Código Penal e a Lei de Execução Penal; e dá outras providências. Brasília - DF; 2006.

12. CARNEVALLE CV, et al. Notificações de violências contra a mulher adulta no Estado de São Paulo em 2014. BEPA, Bol. epidemiol. paul. (Impr.). 2019. 6(181-182):3-17

13. COSTA MS, et al. Violência contra a mulher: descrição das denúncias em um Centro de Referência de Atendimento à Mulher de Cajazeiras, Paraíba, 2010 a 2012.Epidemiologia e Serviços de Saúde [online]. 2015. 24(3): 551-558.

14. FANGER VC, et al. Fatores associados à violência contra mulher na vida pregressa de mulheres encarceradas. REME rev. min. Enfermagem. 2019. 23: e-1249.

15. FERREIRA PC, et al. Caracterização dos casos de violência contra mulheres. JournalofNursing UFPE online. 2020. $14(0)$

16. FIOROTTI K, et al. Prevalência e fatores associados a violência doméstica: estudo em uma maternidade de alto risco. Textocontexto - enferm. 2018.27(3): e0810017

17. VAN DER WALT C. Hearing Tamar's voice: Contextual readings of 2 Samuel 13:1-22. OldTestamentEssays. 2012. 25(1):182-206

18. GUIMARAES RCS, et al. Impacto na autoestima de mulheres em situação de violência doméstica atendidas em Campina Grande, Brasil. RevCuid. 2018. 9(1):1988-97

19. HOEPERS AD, TOMANIK ER. (Co)Construindo Sentidos: O Grupo como dispositivo de enfretamento a violência doméstica contra mulheres.. Psicol. Soc. 2019. 31: e214338.

20. LEITE FMC, et al. Violence against women, Espírito Santo, Brazil. Revista de Saúde Pública [online]. 2017. 51(33). 
21. LEITE FMC, et al. Violência contra a mulher: caracterizando a vítima, a agressão e o autor. Rev. Pesqui. (Univ. Fed. Estado Rio J., 2015. 7(1):2181-2191.

22. LIRA KFS. Relações de gênero, poder e violência contra as mulheres: um estudo sobre o Sertão brasileiro. La ventana. 2019. 6(50): 331-62.

23. LIMA LAA, et al. Marcos e dispositivos legais no combate à violência contra a mulher no Brasil. Rev. Enf. Ref. 2016. SerIV(11): 139-146

24. MAFIOLETTI TM, et al. Violence against women: historical trajectory of a care program (Curitiba - 1997-2014). Rev. Bras. Enferm. 2018.71(6): 2907-2915

25. MASCARENHAS MDM, et al. Análise das notificações de violência por parceiro íntimo contra mulheres, Brasil, 2011 2017. Revista Brasileira de Epidemiologia. 2020. 23(01):1980-5497.

26. OLIVEIRA CAB, et al. Perfil da vítima e características da violência contra a mulher no estado de Rondônia - Brasil. Revista Cuidarte. 2019. 10(1): e573.

27. PINAFI T. Violência contra a Mulher: políticas públicas e medidas protetivas na contemporaneidade. Revista Histórica do Estado de São Paulo. 2007. 21.

28. PINTO LSS, et al. Políticas públicas de proteção à mulher: avaliação do atendimento em saúde de vítimas de violência sexual. Ciênc. saúde coletiva. 2017. 22(5):1501-08.

29. ROSA DOA, et al. Violência provocada pelo parceiro íntimo entre usuárias da Atenção Primária à Saúde: prevalência e fatores associados. Saúde debate. 2018. 42 (spe4): 67-80

30. SAES LAM, MORIN TM. Virtuosas e perigosas: As mulheres na Revolução Francesa. Rev. Hist. (São Paulo). 2014. $171: 461-468$

31. SANTOS DF, et al. Percepção de mulheres acerca da violência vivenciada. Rev. pesqui. cuid. fundam. (Online). 2017. 9(1)

32. SILVA LEL, OLIVEIRA MLC. Características epidemiológicas da violência contra mulher no Distrito Federal, 2009 a 2012. Epidemiologia e Serv. Saúde. 2016. 25(2): 331-342

33. SILVA MPS, et al. A violência e suas repercussões na vida da mulher contemporanêa. Rev. enferm. UFPE online. 2017. 11(8)

34. SINAN. Sistema de informação de agravos de notificação. Dados epidemiológicos Sinan. Portal Sinan. Julho, 2020.

35. SMANIOTTO GRG, et al. Situações de vulnerabilidade a violência vivenciadas por mulheres profissionais do sexo: Um estudo de caso. Cienc. enferm. 2018. 24:8.

36. SIQUEIRA VB, et al. Violência psicológica contra mulheres usuárias da atenção primária à saúde. Rev. APS. 2018. 21(3):437-449.

37. VIANA AL, et al. Violência contra a mulher. Rev. Enferm. UFPE. 2018. 2(4):923-929.

38. ZANCAN N, et al. A violência doméstica a partir do discurso de mulheres agredidas. Pensando fam. 2013. 17(1): 6376. 